\title{
Compounds That Target Novel Cellular Components Involved in HIV-1 Transcription
}

\author{
Salvatore T. Butera,* Beverly D. Roberts,* \\ J. William Critchfield,* Guofu Fang,* Thomas McQuade, ${ }^{\dagger}$ \\ Stephen J. Gracheck, ${ }^{\dagger}$ and Thomas M. Folks*
}

\author{
*Retrovirus Diseases Branch, Division of Viral and Rickettsial \\ Diseases, National Center for Infectious Diseases, Centers \\ for Disease Control and Prevention, Atlanta, Georgia, U.S.A. \\ ${ }^{\dagger}$ Parke-Davis Pharmaceutical Research, Ann Arbor, Michigan, U.S.A.
}

\begin{abstract}
Background: Therapeutic intervention designed to block expression of human immunodeficiency virus (HIV) at a cellular level may slow the clinical progression of HIV-l disease.

Materials and Methods: Cellular models of latent (OM-10.1 and U1) and chronic (8E5) HIV infection were used to evaluate two benzothiophene derivatives, PD 121871 and PD 144795, for an ability to inhibit HIV activation and expression.

Results: The benzothiophene derivatives were effective at micromolar concentrations in preventing tumor necrosis factor $\alpha$ (TNF $\alpha$ )-induced HIV-1 expression in OM10.1 and Ul cultures. These compounds inhibited the activation of HIV-1 transcription; however, this inhibition was selective in that another TNF $\alpha$-induced response, the transcription of autocrine TNF $\alpha$, was unaffected. Constitutive HIV-1 expression by chronically infected 8E5 cells was also significantly reduced when treated with these experimental compounds. In TNF $\alpha$ -
\end{abstract}

treated OM-10.1 cultures, the inhibition of HIV-1 transcription by these compounds was not due to a block of nuclear factor $-\kappa \mathrm{B}$ induction. The benzothiophene derivatives also inhibited HIV-l activation by phorbol ester treatment of OM-10.1 promyelocytes, although no inhibition of cellular differentiation toward a macrophagelike phenotype was observed. Furthermore, these experimental compounds induced a state of HIV-1 latency in cytokine-activated OM-10.1 cultures even when maintained under constant TNF $\alpha$ stimulation. The benzothiophene derivatives did not inhibit the activity of the HIV-1 trans-activator, Tat, when evaluated in transient transfection assays.

Conclusions: The benzothiophene derivatives appear to inhibit a critical cellular component, distinct from nuclear factor $-\kappa \mathrm{B}$, involved in HIV transcription and may serve to identify new therapeutic targets to restrict HIV expression.

\section{INTRODUCTION}

While the influences controlling clinical progression to acquired immunodeficiency syndrome (AIDS) are certainly multifactorial (1), a critical facet is the continued replication of human immunodeficiency virus (HIV) within target cells

Address correspondence and reprint requests to: Salvatore T. Butera, Retrovirus Diseases Branch, Centers for Disease Control and Prevention, 1600 Clifton Road, NE, MS-G19, Atlanta, GA, 30333, U.S.A. and tissues (2) especially late in the disease process $(3,4)$. However, during the clinically asymptomatic period the balance between infected cells actively replicating HIV and those harboring the provirus in a dormant state (5) has not been fully elucidated. Therefore, therapeutic intervention to alter clinical progression to AIDS, especially during the asymptomatic period, must address both the control of active HIV replication and the inhibition of viral activation. 
With the exception of the viral trans-activator Tat, HIV transcription is critically dependent upon host cell transcription machinery. Thus, therapeutic targeting of cellular factors that participate in HIV transcription warrants further development. Among the potential targets is nuclear factor $-\kappa \mathrm{B}(\mathrm{NF}-\kappa \mathrm{B})$, an inducible transcriptional enhancer important for HIV activation (6-8). Antioxidants and other pharmacologic agents that block HIV promoter-directed gene expression may interfere with the dissociation of pre-formed NF- $\kappa \mathrm{B}$ from its cytoplasmic inhibitor, I- $\kappa \mathrm{B}(9-15)$. In addition, inhibition of selected cellular enzymes, including protein kinase C (16) and ribonucleotide reductase (17), has also proven effective against HIV expression. However, targeting of cellular components must retain some degree of viral specificity, otherwise these therapies may interfere with normal cellular and immune functions.

This report focuses on the anti-HIV activity of two benzothiophene derivatives, originally described to prevent the expression of cellular adhesion molecules and alter the outcome of immune complex-induced inflammation (18). In our studies, these compounds selectively inhibited HIV transcription and induced a state of viral latency in HIV-expressing cells by targeting a cellular factor, other than NF- $\kappa$ B. Interruption of HIV transcription by interfering with cellular components could offer novel therapeutic approaches to the management of AIDS.

\section{MATERIALS AND METHODS \\ Cell Lines, Compounds, and Culture Conditions}

The latently and chronically HIV-1 $1_{\text {LAI }}$-infected cell lines used in this study have been previously characterized: promyelocytic OM-10.1 (HL-60derived) (19), promonocytic Ul (U937-derived) (20), and T-lymphocytic 8E5 (A3.01-derived) (21). All cell lines were propagated in RPMI 1640 basal medium (Gibco, Gaithersburg, MD, U.S.A.) containing $10 \%$ fetal bovine serum, $2 \mathrm{mM}$ glutamine, and $1 \%$ Pen-Strep (Gibco) at $37^{\circ} \mathrm{C}$ in a humidified atmosphere of $7 \% \mathrm{CO}_{2}$ and $93 \%$ air.

Two structurally related benzothiophene derivatives, designated PD 121871 and PD 144795 , were synthesized by Parke-Davis Pharmaceuticals as described (18). These compounds were dissolved in dimethyl sulfoxide to $20 \mathrm{mM}$ and further dilutions were made in RPMI 1640 basal medium. The antagonist of HIV-1 trans-activation Ro 5-3335 (22) (obtained from Dr. M. Hsu, Hoffmann-La Roche) was used at $10 \mu \mathrm{M}$.

HIV-1 induction experiments were performed at $5 \times 10^{5}$ cells $/ \mathrm{ml}$ by treatment with either TNF $\alpha$ (Genzyme, Cambridge, MA, U.S.A.), at $20 \mathrm{U}$ per $\mathrm{ml}$ for OM-10.1 cultures and $100 \mathrm{U}$ per $\mathrm{ml}$ for Ul cultures, or 0.1 $\mu \mathrm{M}$ PMA (Sigma Chemical Co., St. Louis, MO, U.S.A.). The experimental compounds were added $2 \mathrm{hr}$ prior to HIV-1 induction. $\left[{ }^{3} \mathrm{H}\right]$-thymidine uptake studies for drug toxicity were performed with $1 \times 10^{5}$ cells in triplicate wells of a 96-well plate during a 36-hr incubation.

\section{Quantitation of HIV-1 Expression}

HIV-1 expression in cell-free culture supernatants was quantitated by RT enzymatic activity using a cocktail containing polyadenylate, oligo (dT), $\mathrm{MgCl}_{2}$, and $\left[\alpha-{ }^{32} \mathrm{P}\right]$-dTTP (23).

\section{Determination of Cell Surface Antigen Expression}

OM-10.1 cells were prepared as described (19) and directly stained with a phycoerythrin-conjugated anti-CD4 monoclonal antibody (Leu-3a, Becton-Dickinson, Mountain View, CA, U.S.A.). The macrophage-specific antibody Mo3e (24) (obtained from Dr. R. Todd, III, University of Michigan) was used in succession with a phycoerythrin-conjugated goat anti-mouse secondary antibody. After the final antibody incubation (30 min at $4^{\circ} \mathrm{C}$ ), cells were washed and fixed before analysis on a Becton Dickinson FACScan system (19).

\section{Northern Blot Analysis of Total Cellular RNA}

Cells were lysed in a guanidine thiocyanate buffer and total RNA was purified and electrophoresed through agarose, as described $(25,26)$. Confirmation of the RNA quantity and integrity was obtained by UV visualization of the ribosomal bands. The separated RNA was then transferred to a nylon membrane (Amersham) and hybridized in a $50 \%$ formamide buffer overnight at $42^{\circ} \mathrm{C}$. A $2.5 \mathrm{~kb}$ PstI- $\mathrm{XbaI}$ digestion fragment of pHXB2 (26), containing the $5^{\prime}$-LTR, was used for HIV-1 RNA detection and an 800-bp EcoRI fragment was used for TNF $\alpha$ mRNA detection (25). Both probes were labeled with $\left[\alpha-{ }^{32} \mathrm{P}\right]$-dCTP by random priming (Amersham Corp., Arlington 
Heights, IL). Prior to autoradiography, the membranes were washed twice at $57^{\circ} \mathrm{C}$ in $2 \times$ standard saline citrate plus $1 \%$ sodium dodecyl sulfate.

\section{Analysis of NF- $\kappa$ B Binding Activity and Function}

Nuclear and cytoplasmic extracts were prepared as described (27) and protein concentrations were determined by the bicinchoninic acid method (Pierce, Rockford, IL). Equivalent amounts of nuclear protein obtained after a 30min TNF- $\alpha$ treatment of OM-10.1 cultures were tested for NF- $\kappa \mathrm{B}$ binding activity using the Gelshift Kit (Stratagene), following the manufacturer's protocol. Cytoplasmic proteins $(70 \mu \mathrm{g}) \mathrm{ob}-$ tained after a 30-min and 2-hr TNF $\alpha$ treatment of OM-10.1 cultures were tested for I- $\kappa$ B regeneration by immunoblot analysis, as described (28), using the anti-I- $\kappa \mathrm{B}$ antibody AR20 (obtained from Dr. J. Hiscott, McGill University). Cyclohexamide was used in these studies at 10 $\mu \mathrm{g} / \mathrm{ml}$ as a positive control to prevent $\mathrm{I}-\kappa \mathrm{B}$ regeneration.

\section{Transient Transfection Assays for Tat Activity}

A3.01 T lymphocytes were cotransfected by electroporation with a plasmid expressing CAT under the control of the HIV-1 LTR (pU3RIIICAT) (29) and a plasmid expressing HIV-1 Tat under the control of the SV40 promoter (pSV tat) (30). Initial titration experiments were performed to insure that LTR-directed CAT expression was linear in response to the input amount of pSV tat plasmid. A3.01 cells were pretreated with the experimental compounds and were harvested 48 hr after electroporation. Cell lysates were adjusted for protein concentration by the bicinchoninic acid method and CAT enzyme levels were quantitated by specific enzyme immunoassay, as described by the manufacturer (BoehringerMannheim, Indianapolis, IN, U.S.A.).

\section{RESULTS}

\section{Experimental Compounds Selectively Inhibit HIV Transcription}

Initial studies of two structurally related benzothiophene derivatives, PD 121871 and PD 144795, for inhibition of HIV expression were
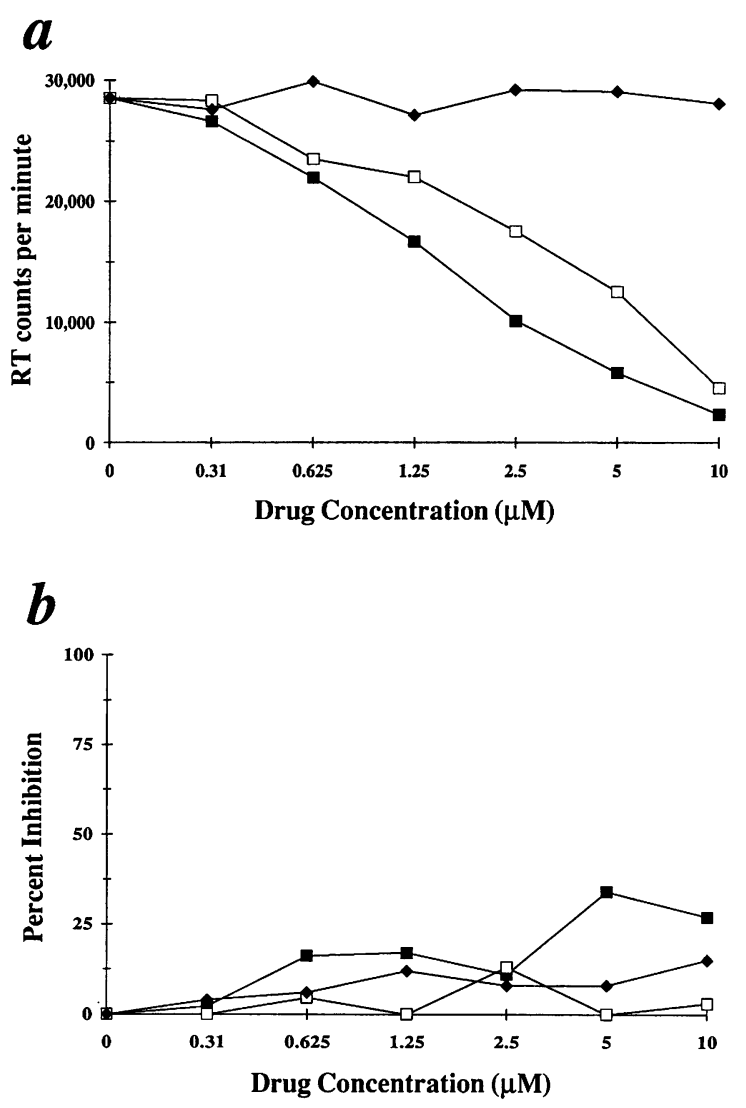

FIG. 1. TNF $\alpha$-induced HIV-1 activation in OM10.1 cultures in the presence of benzothiophene derivatives

(a) Compounds PD 121871 ( $\square$ ) and PD 144795 ( $\square$ ) were added at the indicated concentrations and HIV- 1 activation in OM-10.1 cultures was measured by supernatant RT activity after $48 \mathrm{hr}$ of TNF $\alpha$ treatment. The dimethyl sulfoxide solvent $(\diamond)$ was added relative to the final concentration in drug treated cultures $(0.05 \%$ at $10 \mu \mathrm{M})$. (b) Cellular toxicity of the benzothiophene derivatives over the same concentration range as determined by an inhibition of $\left[{ }^{3} \mathrm{H}\right]$-thymidine uptake. Data are representative of more than five separate experiments.

performed on OM-10.1 cells, a promyelocytic model of latent and inducible HIV-1 infection (19) convenient for screening compounds for postintegration anti-HIV activity (31). As evidenced by the reduction of supernatant reverse transcriptase (RT) activity (Fig. 1 $a$ ), both compounds at concentrations below $10 \mu \mathrm{M}$ dramatically inhibited HIV-1 expression in OM-10.1 cultures treated with recombinant tumor necrosis factor $\alpha(\mathrm{TNF} \alpha)$. In a similar manner, these compounds prevented the down-modulation of cell surface $\mathrm{CD} 4$ that occurs as a direct consequence of viral activation in TNF $\alpha$-treated OM- 


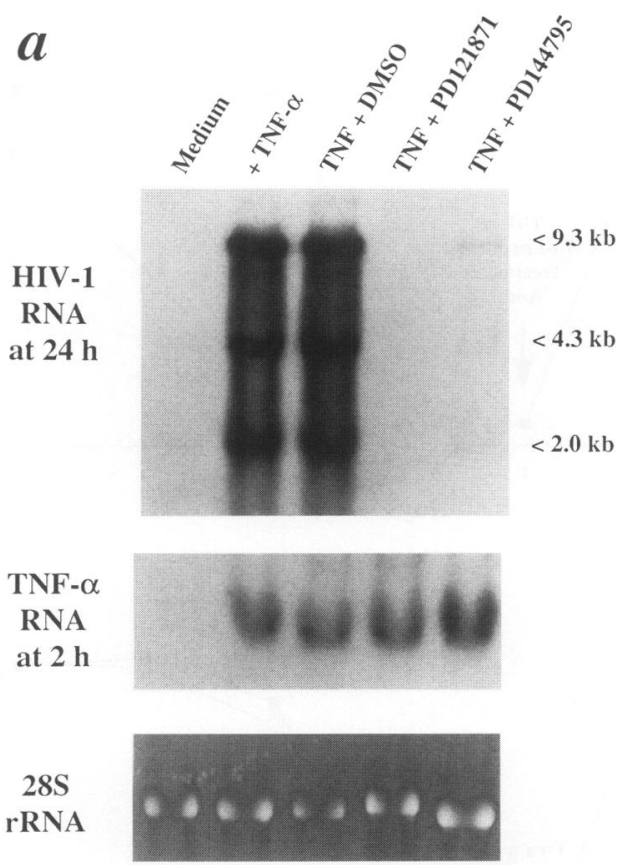

FIG. 2. Analyses of HIV-1 and cellular gene transcription in the presence of benzothiophene derivatives

(a) OM-10.1 cultures were harvested after $2 \mathrm{hr}$ (for autocrine TNF $\alpha$ ) or $24 \mathrm{hr}$ (for HIV-1) of TNF $\alpha$ treatment and total cellular RNA was hybridized with specific probes. Molecular size indicators depict the three well-recognized HIV-1 transcripts. Ethidium bromide-stained 28S ribosomal RNA is shown to verify the quantity and integrity of each sample. (b) HIV-1 transcription after TNF $\alpha$ induction of U1 promocytes and in constitutively expressing 8E5 cultures (c) PMA-induced HIV-1 transcription (upper) and cellular differentiation (lower) in OM-10.1 promyelocytes. Macrophage-like differentiation was determined by flow cytometric analysis of Mo3e surface expression before $(-\cdot-)$ and $24 \mathrm{hr}$ after PMA treatment (-) and $24 \mathrm{hr}$ after PMA treatment in the presence of PD 121871 ( - -) or PD 144795 (- - - ). Data are representative of more than five separate experiments.

10.1 cultures $(19,31)$ (data not shown), suggesting an inhibition of HIV transcription or translation (31). These compounds were well tolerated by OM-10.1 cells, and the inhibition of thymidine incorporation was approximately $25 \%$ or less over the concentration range tested (Fig. $1 b$ ).
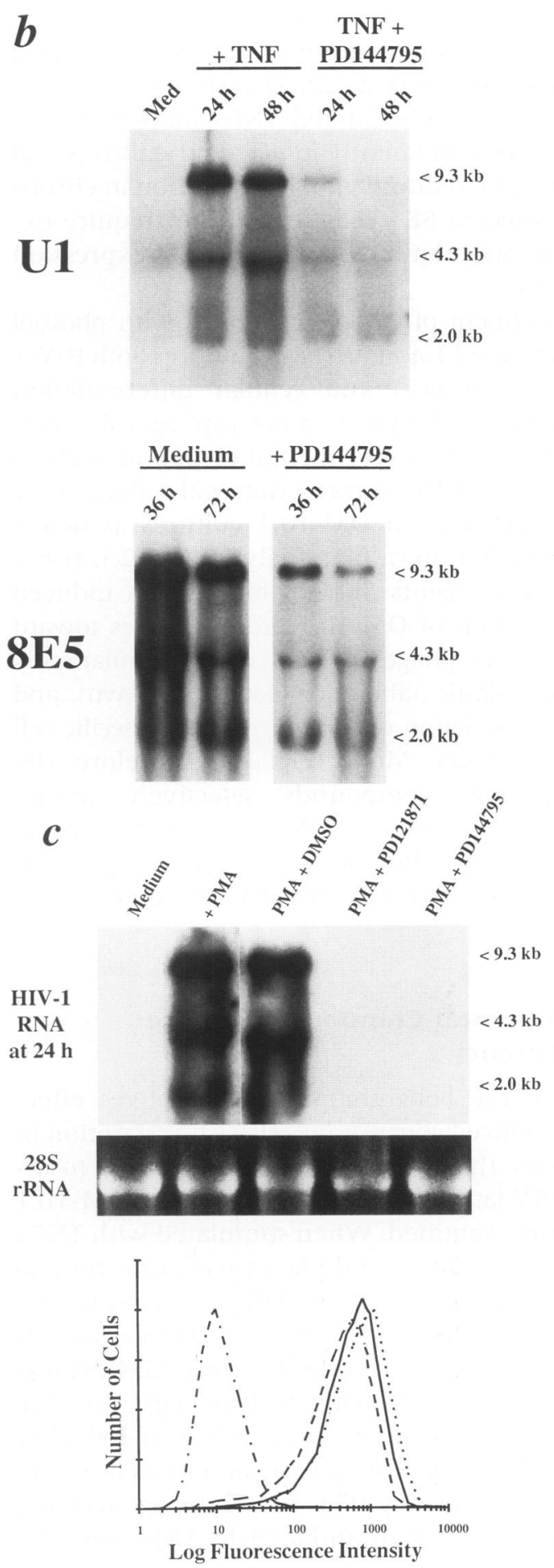

Northern blot analysis demonstrated that the benzothiophene derivatives inhibited HIV transcription, effectively preventing HIV-1 mRNA accumulation during a 24-hr TNF $\alpha$ induction of OM-10.1 cells (Fig. 2a). The inhibition of HIV transcription was selective in that another cellu- 
lar response to exogenous TNF $\alpha$ stimulation, the transcription of autocrine TNF $\alpha$, was unaffected by these agents (Fig. $2 a$ ). The benzothiophene compounds also inhibited TNF $\alpha$-induced HIV-l transcription in latently infected Ul cultures and significantly reduced viral transcription in chronically infected $8 \mathrm{E} 5$ cells that do not require exogenous stimulation to activate HIV-1 expression (Fig. 2b).

Treatment of OM-10.1 cultures with phorbol 12-myristate 13-acetate (PMA) induces both HIV-1 transcription (19) and cellular differentiation from a promyelocytic to a macrophage-like phenotype (7). The experimental compounds effectively blocked HIV-1 transcriptional activation by PMA treatment in OM-10.1 cultures as determined by Northern blot analysis (Fig. 2c). However, these agents did not block PMA-induced differentiation of OM-10.1 promyelocytes toward mature macrophages, as evaluated by cellular morphology, plastic adherence (data not shown), and an up-modulation of the macrophage-specific cell surface marker, Mo3e (Fig. 2c). Therefore, the experimental compounds selectively inhibit phorbol ester-induced HIV-1 transcription without disrupting the coordinated transcription of other cellular genes required for differentiation.

\section{Experimental Compounds Induce HIV Latency}

Because the benzothiophene derivatives effectively reduced constitutive HIV-1 transcription in $8 \mathrm{E} 5$ cells, the ability of these compounds to induce HIV latency in actively expressing OM-10.1 cells was examined. When stimulated with TNF $\alpha$ for $24 \mathrm{hr}$, washed, and placed back into normal culture medium, activated OM-10.1 cells gradually returned to a state of viral latency, as evidenced by the return of cell surface CD4 expression, over the following 5 days (Fig. $3 a$ ). The benzothiophene derivatives, when added after the TNF $\alpha$ stimulation, greatly accelerated the return to viral latency (Fig. 3a). These agents were also applied after an initial 24-hr TNF $\alpha$ stimulation, but in the continued presence of exogenous TNF $\alpha$ (Fig. $3 b$ ). In these studies, the inhibitory activity of the benzothiophene derivatives prevailed over the continued TNF $\alpha$ stimulation and the activated OM-10.1 cells were forced into viral latency within the following $48 \mathrm{hr}$. The compounds were well tolerated during the 5-day culture period and no loss of cell viability was observed.
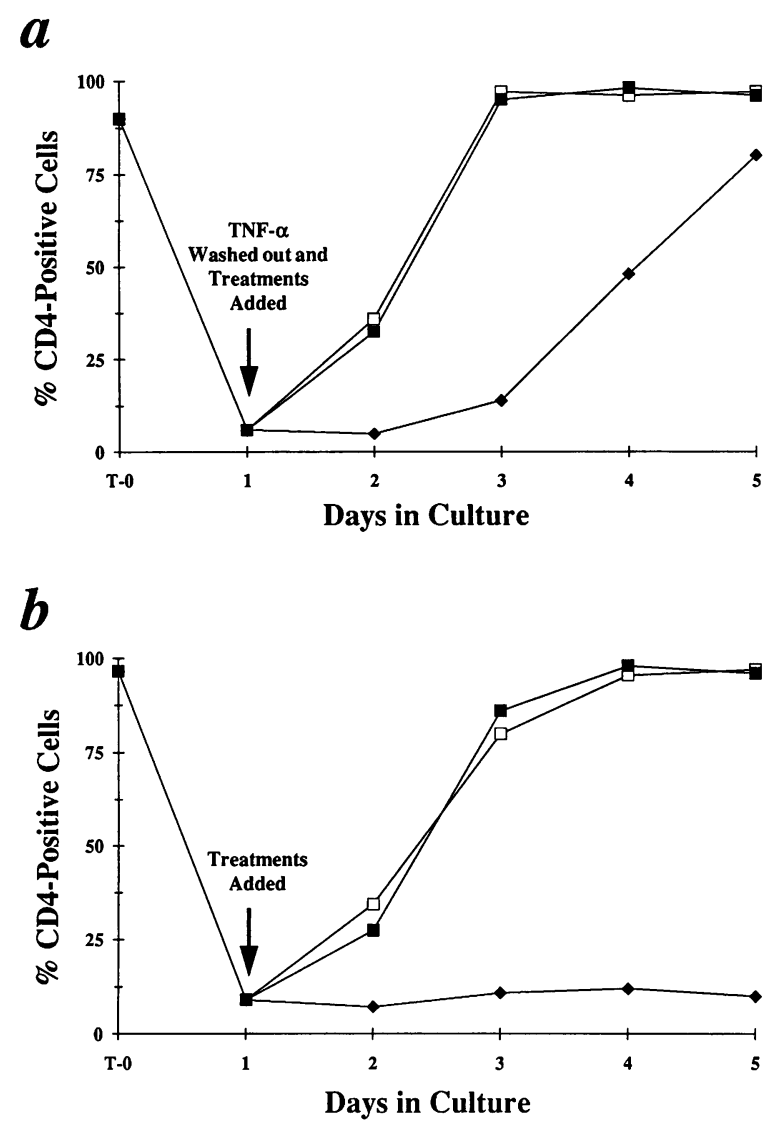

FIG. 3. Effect of benzothiophene compounds on the return to HIV-1 latency in TNF $\alpha$-stimulated OM-10.1 cultures

OM-10.1 cultures were first treated for $24 \mathrm{hr}$ with TNF $\alpha$ to allow for maximum viral activation and then (a) the exogenous TNF $\alpha$ was washed out and the cells were placed into medium $(\diamond)$ or in medium containing either PD $121871(\square, 5 \mu \mathrm{M})$ or PD $144795(\square, 10 \mu \mathrm{M})$, and (b) the cells were maintained in medium containing TNF $\alpha(\diamond)$ or in medium containing TNF $\alpha$ and either PD $121871(\boldsymbol{\square}$ $5 \mu \mathrm{M})$ or PD $144795(\square, 10 \mu \mathrm{M})$. The cultures were monitored for a return to viral latency by the reappearance of surface CD4, an inverse indicator of HIV-1 expression in OM-10.1 cultures, over a 4-day period. Data are indicative of more than three separate experiments.

\section{Experimental Compounds Permit NF- $\kappa$ B Activation}

The activation of preformed NF- $\kappa \mathrm{B}$ is generally considered a critical third messenger in the TNF receptor signaling pathway $(27,32)$ and an important enhancer of HIV transcription (6-8). Therefore, gel-shift analyses were performed to determine if the experimental compounds altered NF- $\kappa$ B activation or translocation. Gel-shift 
$a$

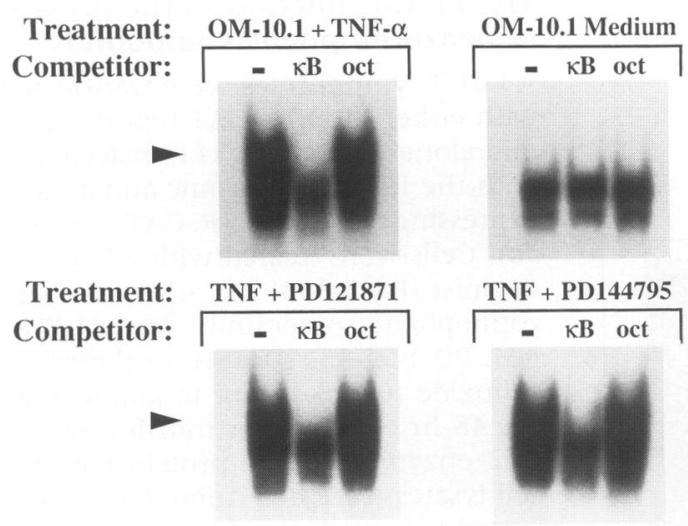

FIG. 4. NF-kB activation and function after TNF $\alpha$ treatment of OM-10.1 cells in the presence of benzothiophene derivatives

(a) Nuclear extracts from 30-min $\mathrm{TNF} \alpha$-treated OM10.1 cultures were interacted with a labeled NF- $\kappa \mathrm{B}-$ specific probe either alone $(-)$ or in combination with an 24-fold excess of unlabeled specific $(\kappa \mathrm{B})$ and nonspecific (oct) competitor probes. The bound

products of these reactions were identified by electrophoresis and autoradiography. TNF $\alpha$-induced, NF- $\kappa \mathrm{B}-$ specific binding activity is marked by the arrow. (b) Cytoplasmic extracts from OM-10.1 cultures before (T-0) and at various times ( $30 \mathrm{~min}$ and $2 \mathrm{hr}$ ) after TNF $\alpha$ treatment were tested by immunoblot analysis for I- $\kappa \mathrm{B}$. A corresponding medium culture (not TNF $\alpha$ treated) was harvested at each time point. The band shown migrated to $37 \mathrm{kD}$, characteristic of $\mathrm{I}-\kappa \mathrm{B}$.

analysis clearly demonstrated the release and nuclear translocation of NF- $\kappa$ B after TNF $\alpha$ stimulation of OM-10.1 cells in the presence of the benzothiophene derivatives (Fig. $4 a$ ). The experimental compounds neither reduced the quantity of NF- $\kappa$ B binding activity (as determined by serial titrations of nuclear protein preparations into the binding reaction) nor inhibited the binding of active NF- $\kappa$ B to its DNA motif when added directly to the in vitro binding reaction (data not shown).

Furthermore, the functionality of NF- $\kappa \mathrm{B}$ in the presence of the experimental compounds was confirmed by examining the induced transcription of another NF- $\kappa \mathrm{B}$-dependent gene, I- $\kappa \mathrm{B}$ (33). Upon TNF $\alpha$ stimulation, preformed NF- $\kappa \mathrm{B}$ is activated by the phosphorylation and proteolytic degradation of its cytosolic inhibitor, I- $\kappa \mathrm{B}(34,35)$. Active NF- $\kappa \mathrm{B}$ then participates in a self-regulated negative feedback loop by transcriptionally regenerating I- $\kappa \mathrm{B}(28,33,36)$. In immunoblot analyses, the rapid degradation and regeneration of $I-\kappa B$ was readily apparent after TNF $\alpha$ stimulation of OM-10.1 cells and I- $\kappa \mathrm{B}$ regeneration was not inhibited by the addition of the experimental compounds (Fig. 4b). $\boldsymbol{b}$

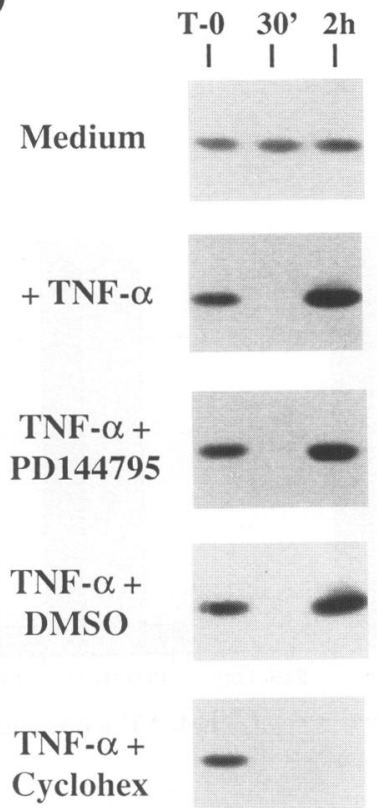

\section{Experimental Compounds Do Not Inhibit Tat Activity}

Because many of these same effects could result from an inhibition of the viral transactivator Tat $(22,37)$, transient transfection experiments were performed to examine Tat function in the presence of the benzothiophene derivatives (Fig. 5). Cotransfection of a constitutive Tat expression plasmid and a plasmid expressing chloramphenicol acetyltransferase under the control of the HIV-1 long terminal repeat (LTR-CAT) resulted in a large increase of CAT protein as compared with transfection of the LTR-CAT plasmid alone. The addition of the antagonist of Tat trans-activation, Ro 5-3335, markedly reduced the expression of CAT protein in cotransfected cells. However, no reduction of CAT protein was observed when either of the benzothiophene derivatives was added (Fig. 5). Therefore, the benzothiophene derivatives do not interfere with Tat function as the primary mechanism to inhibit HIV-1 transcription. 


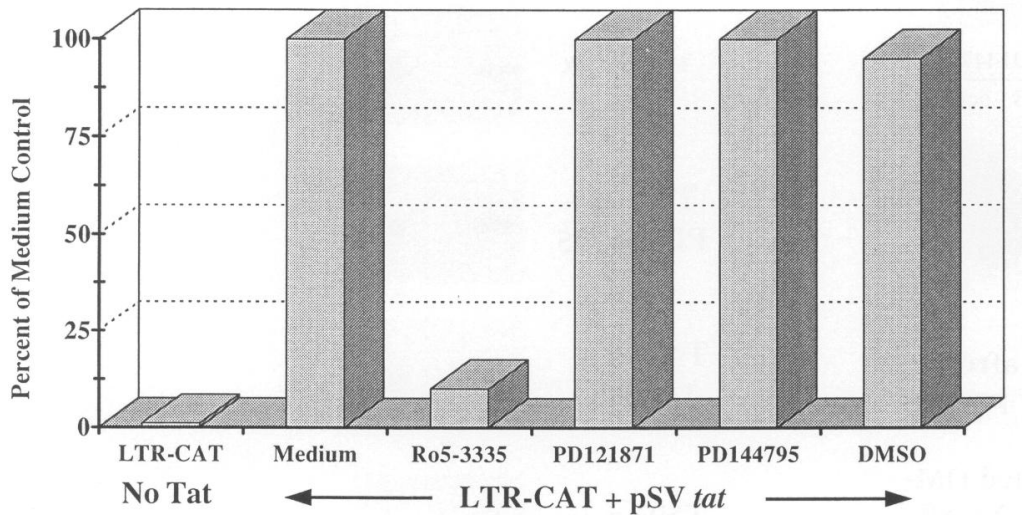

FIG. 5. Transient transfection assay for Tat function in the presence of benzothiophene compounds

A3.01 T lymphocytes were transfected with either the LTR-CAT reporter plasmid alone (No Tat) or cotransfected with the LTR-CAT plasmic and a Tat expressing plasmid (LTR-CAT + pSV tat). Cells were treated with a Tat antagonist (Ro 5-3335, $10 \mu \mathrm{M}$ ), the benzothiophene compounds (PD 121871, 5 $\mu \mathrm{M}$; PD 144795, $10 \mu \mathrm{M})$, or dimethyl sulfoxide $(0.05 \%)$ prior to and during the 48-hr culture after transfection. CAT enzyme levels in protein-adjusted cell lysates were determined and converted to a percentage of medium control (values in excess of the medium control were set to $100 \%$ ). Data represent similar results from more than 10 separate experiments with the benzothiophene derivatives and three separate experiments with Ro 5-3335.

\section{DISCUSSION}

We have characterized the activity of two benzothiophene derivatives that, at micromolar concentrations, inhibited HIV transcription in models of latent and chronic infection. Furthermore, these compounds induced a state of viral latency in cells actively expressing HIV, even when maintained under conditions of constant viral stimulation. The benzothiophene compounds selectively inhibited HIV transcription by a mechanism not involving Tat function or NF- $\kappa \mathrm{B}$ activation. Taken together, these findings provide evidence for the therapeutic inhibition of a novel cellular target essential for HIV transcription.

In many of our studies, the benzothiophene derivatives were characterized by an ability to block TNF $\alpha$-induced HIV activation. However, these agents do not appear to act primarily as TNF antagonists. Consistent with this, these agents did not inhibit NF- $\kappa$ B activation or autocrine TNF $\alpha$ transcription in response to TNF $\alpha$ treatment of OM-10.1 cells. Also, these agents inhibited HIV-I transcription in chronically infected 8E5 cells that express HIV-1 independent of exogenous stimulation. Therefore, in vivo, these compounds may lack the potential immunosuppressive side effects of other anti-HIV agents targeting NF- $\kappa \mathrm{B}$ activation or other elements of the TNF $\alpha$ response pathway.

The fact that the benzothiophene compounds did not interfere with the function of Tat, the lone recognized viral protein involved in tran- scriptional activation and elongation, strongly suggests that these agents target a cellular component of the HIV transcription complex rather than a virally encoded factor. This is further established by the observation in cell systems not involving HIV that these agents prevent the expression of surface adhesion molecules (18), implying cellular cofactor involvement. As with therapeutic targeting of any cellular factor, the issue of relative selectivity for HIV transcription needs to be closely examined. Since these agents did not block the transcription of autocrine TNF $\alpha$ in OM10.1 cells, general transcriptional function appeared to not be affected. More impressively, these agents did not alter differentiation of promyelocytes toward macrophages, a biologic response that certainly requires the coordinated transcription of many cellular genes. While the exact target of these compounds awaits identification, it appears restricted in its involvement to the transcription of only a limited subset of genes.

The involvement of NF- $\kappa \mathrm{B}$ in the activation of HIV transcription is well documented (6-8), although NF- $\kappa \mathrm{B}$ may not always be an absolute requirement for HIV-1 activation (38). The experimental compounds tested here neither inhibited NF- $\kappa$ B activation nor altered the ability of $N F-\kappa B$ to bind its DNA motif. Furthermore, the functionality of NF- $\kappa \mathrm{B}$ in the presence of these compounds was confirmed by the transcription of a cellular gene, I- $\kappa \mathrm{B}$, dependent on NF- $\kappa \mathrm{B}$ $(28,33,36)$. However, by inhibiting additional 
cellular components, these compounds demonstrated that the activation of NF- $\kappa$ B was not sufficient to induce HIV transcription. This same observation has been reported in transient transfection systems $(39,40)$ and in HIV-1-infected primary human astrocytes $(41)$.

The possibility remains that the target of therapeutic inhibition is a factor that must interact with or work in concert with NF- $\kappa \mathrm{B}$ in a selective manner to achieve HIV transcriptional activity $(42,43)$. In this regard, DNA footprint analysis of the HIV promoter in the presence of the benzothiophene derivatives may illucidate alterations in the cellular transcription components. Other possible cellular modifications have been considered as targets of the benzothiophene derivatives, including the need for nucleosomal unraveling at the HIV promoter to allow viral transcription (44). However, preliminary studies demonstrated that the HIV promoter dissociated from its nucleosomal arrangement, becoming accessible to enzymatic digestion (44), in the presence of the experimental compounds (S. Butera and $\mathrm{E}$. Verdin, manuscript in preparation).

During all stages of clinical progression to AIDS, HIV expression continues $(1,2)$ and may well contribute to the accumulative destruction of the immune system $(3,4)$. Therefore, in the context of anti-HIV intervention, the therapeutic induction of viral latency in cells actively expressing HIV would be a new approach to reduce the viral burden and slow disease progression. These benzothiophene derivatives accelerated the return to viral latency in OM-10.1 cultures when the extracellular stimulus was removed and induced a state of viral latency in the presence of continued viral stimulation. These compounds also inhibited HIV-1 expression in constitutively expressing 8E5 cells and severely restricted viral expression during an acute infection of MT-4 T cells (data not shown), possibly targeting post-integration events. The broad inhibitory activity of these compounds indicates that their intracellular target is an important component of the HIV transcriptional complex whose requirement is independent of cell lineage variation and the site of viral integration.

Therapeutic control of viral transcription in cells expressing HIV constitutes an appealing intervention and a potential supplement to other pharmacologic agents targeting viral-specific gene products. With the identification of the molecular target, these experimental compounds may elucidate new cellular processes that prevent HIV expression and provide a means of prolonging the clinically asymptomatic phase that precedes AIDS.

\section{ACKNOWLEDGMENTS}

The authors gratefully acknowledge the contributions of Diane H. Boschelli and James B. Kramer for the chemical synthesis of PD 121871 and PD 144795 and Drs. Diane Pardi, Eric Verdin, and Gary Nabel for helpful discussions and critical review of the manuscript.

\section{REFERENCES}

1. Pantaleo G, Graziosi C, Fauci AS. (1993) The immunopathogenesis of human immunodeficiency virus infection. $N$. Engl. J. Med. 328: 327-335.

2. Pantaleo G, Graziosi C, Demarest JF. (1993) HIV infection is active and progressive in lymphoid tissue during the clinically latent stage of disease. Nature 362: 355-358.

3. Wei X, Ghosh SK, Taylor ME. (1995) Viral dynamics in human immunodeficiency virus type 1 infection. Nature 373: 117-122.

4. Ho DD, Neumann AU, Perelson AS, Chen W, Leonard JM, Markowitz M. (1995) Rapid turnover of plasma virions and CD4 lymphocytes in HIV-1 infection. Nature 373: 123126.

5. Embretson J, Zupancic M, Ribas JL. (1993) Massive covert infection of helper T lymphocytes and macrophages by HIV during the incubation period of AIDS. Nature 362: 359362.

6. Duh EJ, Maury W, Folks TM, Fauci AS, Rabson AB. (1989) Tumor necrosis factor-alpha activates human immunodeficiency virus- 1 through induction of nuclear factor binding to the NF- $\kappa \mathrm{B}$ sites in the long terminal repeat. Proc. Natl. Acad. Sci. U.S.A. 86: 59745978.

7. Griffin GE, Leung K, Folks TM, Kunkel S, Nabel GJ. (1989) Activation of HIV gene expression during monocytic differentiation by induction of NF- $\kappa \mathrm{B}$. Nature 339: 70-73.

8. Osborn L, Kunkel S, Nabel GJ. (1989) Tumor necrosis factor $\alpha$ and interleukin 1 stimulate the human immunodeficiency virus enhancer by activation of the nuclear factor $\kappa \mathrm{B}$. Proc. Natl. Acad. Sci. U.S.A. 86: 2336-2340.

9. Ghosh S, Baltimore D. (1990) Activation in 
vitro of NF- $\kappa \mathrm{B}$ by phosphorylation of its inhibitor I $\kappa$ B. Nature 344: 678-682.

10. Fazely F, Dezube BJ, Allen-Ryan J, Pardee AB, Ruprecht RM. (1991) Pentoxifylline (Trental) decreases the replication of the human immunodeficiency virus type 1 in human peripheral blood mononuclear cells and in cultured T cells. Blood 77: 1653-1656.

11. Kopp E, Ghosh S. (1994) Inhibition of NF- $\kappa$ B by sodium salicylate and aspirin. $S c i-$ ence 265: 956-959.

12. Li CJ, Zhang LJ, Dezube BJ, Crumpacker CS, Pardee AB. (1993) Three inhibitors of type 1 human immunodeficiency virus long terminal repeat-directed gene expression and virus replication. Proc. Natl. Acad. Sci. U.S.A. 90: 1839-1842.

13. Mihm S, Ennen J, Pessara U, Kurth R, Dröge W. (1991) Inhibition of HIV-1 replication and NF- $\kappa$ B activity by cysteine and cysteine derivatives. AIDS 5: 497-503.

14. Roederer M, Staal FJ, Raji PA, Ela SW, Herzenberg LA, Herzenberg LA. (1990) Cytokine-stimulated human immunodeficiency virus replication is inhibited by $N$-acetyl-Lcysteine. Proc. Natl. Acad. Sci. U.S.A. 87: 4884-4888.

15. Li CJ, Dezube BJ, Biswas DK, Ahlers CM, Pardee AB. (1994) Inhibitors of HIV-1 transcription. Trends Micro. 2: 164-169.

16. Qatsha KA, Rudolph C, Maemé D, Schächtele C, May WS. (1993) Gö 6976, a selective inhibitor of protein kinase $\mathrm{C}$, is a potent antagonist of human immunodeficiency virus 1 induction from latent/low-level-producing reservoir cell in vitro. Proc. Natl. Acad. Sci. U.S.A. 90: 4674-7678.

17. Lori F, Malykh A, Cara A. (1995) Hydroxyurea as an inhibitor of human immunodeficiency virus-type 1 replication. Science 266: 801-805.

18. Boschelli DH, Kramer JB, Connor DT. (1994) 3-alkoxybenzo [b]thiophene-2-carboxamides as inhibitors of neutrophil-endothelial cell adhesion. J. Med. Chem. 37: 717718.

19. Butera ST, Perez VL, Wu B-Y, Nabel GJ, Folks TM. (1991) Oscillation of the human immunodeficiency virus surface receptor is regulated by the state of viral activation in a $\mathrm{CD} 4^{+}$cell model of chronic infection. J. Virol. 65: 4645-4653.

20. Folks TM, Justement J, Kinter A. (1988) Characterization of a promonocyte clone chronically infected with HIV and inducible by 13-phorbol-12-myristate acetate. J. Immunol. 140: 1117-1122.

21. Folks TM, Powell D, Lightfoote M. (1986) Biological and biochemical characterization of a cloned Leu- $3^{-}$cell surviving infection with the acquired immune deficiency syndrome retrovirus. J. Exp. Med. 164: 280-290.

22. Hsu M-C, Schutt AD, Holly M. (1991) Inhibition of HIV replication in acute and chronic infections in vitro by a Tat antagonist. Science 254: 1799-1802.

23. Willey RL, Smith DH, Lasky LA. (1988) In vitro mutagenesis identifies a region within the envelope gene of the human immunodeficiency virus that is critical for infectivity. J. Virol. 62: 139-147.

24. Todd III RF, Liu DY. (1986) Mononuclear phagocyte activation: Activation-associated antigens. FASEB Proc. 45: 2829-2836.

25. Butera ST, Roberts BD, Folks TM. (1993) Regulation of HIV-1 expression by cytokine networks in a $\mathrm{CD} 4^{+}$model of chronic infection. J. Immunol. 150: 625-634.

26. Butera ST, Roberts BD, Lam L, Hodge T, Folks TM. (1994) Human immunodeficiency virus type 1 RNA expression by four chronically infected cell lines indicates multiple mechanisms of latency. J. Virol. 68: 27262730.

27. Schüze S, Potthoff $K$, Machleidt T, Berkovic D, Wiegmann K, Krönke M. (1992) TNF activates NF- $\kappa \mathrm{B}$ by phosphatidylcholine-specific phospholipase C-induced "acidic" sphingomyelin breakdown. Cell 71: 765-776.

28. Pepin N, Roulston A, Lacoste J, Lin R, Hiscott J. (1994) Subcellular redistribution of HTLV-I Tax protein by NF- $\kappa \mathrm{B} /$ Rel transcription factors. Virology 204: 706-716.

29. Rosen CA, Sodroski JG, Haseltine WA. (1985) The location of cis-acting regulatory sequences in the human $\mathrm{T}$ cell lymphotropic virus type III (HTLV-III/LAV) long terminal repeat. Cell 41: 813-823.

30. Bacheler LT, Strehl LL, Neubauer RH, Petteway Jr SR, Ferguson BQ. (1989) Stable indicator cell lines exhibiting HIV-1 tat function. AIDS Res. Hum. Retrovir. 5: 275-278.

31. Feorino PM, Butera ST, Folks TM, Schinazi RF. (1993) Prevention of activation of HIV-1 by antiviral agents in OM-10.1 cells. Antiviral Chem. Chemother. 4: 55-63.

32. Hohmann H-P, Remy R, Poschl B, Van Loon APGM. (1990) Tumor necrosis factors- $\alpha$ and $-\beta$ bind to the same two types of tumor 
necrosis factor receptors and maximally activate the transcription factor NF- $\kappa \mathrm{B}$ at low receptor occupancy and within minutes after receptor binding. J. Biol. Chem. 265: $15183-$ 15188.

33. Le Bail $O$, Schmidt-Ullrich $R$, Israel $A$. (1993) Promoter analysis of the gene encoding the $I \kappa \mathrm{B}-\alpha / \mathrm{MAD} 3$ inhibitor of NF- $\kappa \mathrm{B}$ : Positive regulation by members of the rel/ NF- $\kappa$ B family. EMBO J. 12: 5043-5049.

34. Beg AA, Finco TS, Nantermet PV, Baldwin Jr AS. (1993) Tumor necrosis factor and interleukin-1 lead to phosphorylation and loss of $\mathrm{I} \kappa \mathrm{B} \alpha$ : A mechanism for NF- $\kappa \mathrm{B}$ activation. Mol. Cell. Biol. 13: 3301-3310.

35. Henkel T, Machleidt T, Alkalay I, Krönke $M$, Ben-Neriah Y, Baeuerle PA. (1993) Rapid proteolysis of $I \kappa B-\alpha$ is necessary for activation of transcription factor NF- $\kappa$ B. Nature 365: 182-185.

36. Sun S-C, P. Ganchi A, Ballard DW, Greene WC. (1993) NF- $\kappa B$ controls expression of inhibitor $\mathrm{I} \kappa \mathrm{B} \alpha$ : Evidence for an inducible autoregulatory pathway. Science 259: 1912-1915.

37. Shahbuddin M, Volsky B, Hsu M-C, Volvsky DJ. (1992) Restoration of cell surface CD4 expression in human immunodeficiency virus type 1 -infected cells by treatment with a Tat antagonist. J. Virol. 66: 6802-6805.

38. Antoni BA, Rabson AB, Kinter A, Bodkin $M$, Poli G. (1994) NF- $\kappa B$-dependent and -independent pathways of HIV activation in a chronically infected $\mathrm{T}$ cell line. Virology 202: 684-694.

Contributed by A. S. Fauci on July 21, 1995.
39. Hazan U, Thomas D, Alcami J. (1990) Stimulation of a human T-cell clone with antiCD3 or tumor necrosis factor induces NF- $\kappa \mathrm{B}$ translocation but not human immunodeficiency virus 1 enhancer-dependent transcription. Proc. Natl. Acad. Sci. U.S.A. 87: 78617865.

40. Doppler C, Schalasta G, Amtmann E, Sauer G. (1992) Binding of NF- $\kappa$ B to the HIV-l LTR is not sufficient to induce HIV-1 LTR activity. AIDS Res. Hum. Retrovir. 8: 245-252.

41. Conant K, Atwood WJ, Traub R, Tornatore C, Major EO. (1994) An increase in p50/p65 NF- $\kappa \mathrm{B}$ binding to the HIV-I LTR is not sufficient to increase viral expression in the primary human astrocyte. Virology 205: 586590.

42. Stein B, Baldwin Jr AS, Ballard DW, Greene WC, Angel P, Herrlich P. (1993) Cross-coupling of the NF- $\kappa \mathrm{B}$ p 65 and Fos/Jun transcription factors produces potentiated biological function. EMBO J. 12: 3879-3891.

43. Perkins ND, Edwards NL, Duckett CS, Agranoff AB, Schmid RM, Nabel GJ. (1993) $A$ cooperative interaction between NF- $\kappa B$ and $\mathrm{Spl}$ is required for HIV-1 enhancer activation. $E M B O \mathrm{~J}$. 12: 3551-3558.

44. Verdin E, Paras Jr P, Van Lint C. (1993) Chromatin disruption in the promoter of human immunodeficiency virus type 1 during transcriptional activation. EMBO J. 12: 32493259. 